Journal of Engineering and Applied Sciences 14 (3): 709-716, 2019

ISSN: 1816-949X

(C) Medwell Journals, 2019

\title{
Risk Reduction of Thermal Damages of Units in Machinery Heat Preparation for Load Acceptance
}

\author{
${ }^{1}$ Ildar Gabitov, ${ }^{1}$ Andrei Negovora, ${ }^{2}$ Eduard Khasanov, ${ }^{3}$ Rustam Galiullin, ${ }^{4}$ Mars Farhshatov, ${ }^{2}$ Rim \\ Khamaletdinov, ${ }^{5}$ Vladimir Martynov, ${ }^{6}$ Dmitryi Gusev, ${ }^{4}$ Nail Yunusbaev and ${ }^{1}$ Mahmut Razyapov \\ ${ }^{1}$ Department of Automobiles and Machine-Tractor Complexes, \\ ${ }^{2}$ Department of Communal and Agricultural Machines, \\ ${ }^{3}$ Department of Electricity Supply and Application of Electric Energy in Agriculture, \\ ${ }^{4}$ Department of Metal Technology and Vehicles Repair, \\ ${ }^{5}$ Department of Life Safety and Process Equipment, \\ ${ }^{6}$ Department of Materials Science and Engineering Graphics, \\ Federal State Budgetary Educational Establishment of Higher Education, \\ Bashkir State Agrarian University, 50-Letia Octyabrya Street 34, Ufa, Russia
}

\begin{abstract}
The study deals with a new method for heat preparation of machinery for the load acceptance by volumetric heating of units using coolant flow with a temperature lowered to $1500^{\circ} \mathrm{C}$ which is regulated by means of a guide device and a steam generator. The interaction of the coolant flow with the heated object is described mathematically, thermal and physical properties of the coolant and the design features of the devices that form the intensity of its heating are revealed. It is substantiated that in order to ensure minimum heat treatment time for the units with a low-temperature coolant, it is necessary to optimize the flow velocity in the gap clearance "guide device-unit wall" and the water flow for the formation of a mixed-type coolant.
\end{abstract}

Key words: Heat preparation, thermal damage, a mixed-type coolant, thermal and physical properties of the coolant, substantiated, temperature

\section{INTRODUCTION}

Modern technology includes a large number of parts made of polymer materials, electronic components and connecting wires that have a low temperature strength loss (up to $150^{\circ} \mathrm{C}$ ). At the same time a significant part of the machine usage period takes place during the cold season at temperatures below $-20^{\circ} \mathrm{C}$ (Gabitov and Negovora, 2015). In some northern regions the winter season lasts up to 300 days. Often drivers do not pay due attention to the preparation of machinery for starting-up and load acceptance in low temperature conditions, although, the viscosity of lubricating and power fluids increases substantially under the influence of low temperatures which leads to unit abnormality and increases the failure risk. All of this indicates the need for the organizing heat preparation of machinery.

The review of methods and devices for cold-weather modifications of machines has allowed to establish that the proposed solutions for organizing heat preparation of units are aimed only at duration reduction of heat preparation and don't take into account the risk of thermal damage of parts. It is obvious that the existing methods and ways of heat preparation are outdated and have a number of disadvantages that make their use difficult.

Overview of existing researches and comparison of new technical solutions (Bogdanic, 2007; Henein, 2007; Bals et al., 2008; Liebl et al., 2009; Georg, 2010) showed that main defect of modern heat preparation techniques is high temperature of the coolant, i.e., hot gas-air mixture which reaches $700^{\circ} \mathrm{C}$ (Negovora and Bairamov, 2008). The science hasn't solved yet, the problem of thermal damage of separate parts and failure of expensive units at thermal preparation of cars.

At present methods for reducing the coolant temperature by means of ejection or stationary steam heating are known and the use of a mixed-type coolant has not been investigated. We studied the heating of units with a mixed-type coolant having a

Corresponding Author: Eduard Khasanov, Department of Communal and Agricultural Machines, Federal State Budgetary Educational Establishment of Higher Education, Bashkir State Agrarian University, 50-Letia Octyabrya Street 34, Ufa, Russia 
working temperature lowered to $150^{\circ} \mathrm{C}$ (Negovora and Gusev, 2013, 2017). The purpose of researches is to solve the problem of thermal damage of units by using a mixed type heat carrier with a reduced temperature to preserve thermal power of the heater and without increasing thermal preparation timing.

\section{MATERIALS AND METHODS}

Main indicator that characterizes the effectiveness of thermal preparation of a unit is the time $\tau$ necessary to heat the unit to a temperature at which the unit can function properly. For a theoretical explanation of the heating process of the unit necessary conditions and assumptions are made. The time that it takes for thermal preparation of a unit depends on the temperature of the coolant $t$, Temperature of the unit $T_{i}$, Temperature of the environment $\mathrm{T}_{0}$, on the qualities of the unit that is being heated such as material, shape and mass. Taking in account uncontrollable factors, the process can be described as equations of fields with distribution of temperature, pressure and speed for non-stationary process of heat transfer.

Taking in account, that in our situation the speed of gas-air mixture, that washes the walls of the unit is no more than $2.5 \mathrm{~m} / \mathrm{sec}$ and number of Maxa $<0.3$, processes of heat exchange and movement of gas can be simplified and described as a system of equations for non-compressional liquid with changing physical properties:

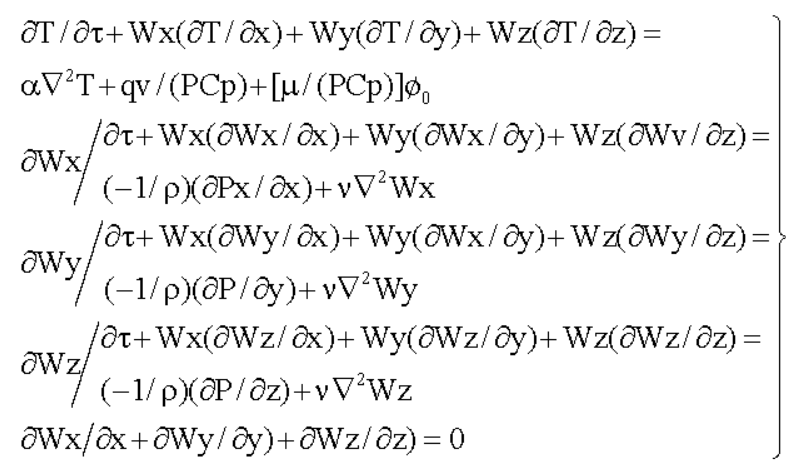

The system of equations is solved in the Flow Vision 2.5 program relying on the Navier-Stokes equations, energy and transference of turbulent functions with given initial and boundary conditions (Gabitov et al., 2007). As a result of modeling the heating process of the oil crankcase in the engine of KAMAZ 740.30 pressure and speed fields were found in space, bounded by a guide and crankcase in different moments during heat preparation. One of the windows of visualization of calculation result is shown in Fig. 1.

For determination of heat flow Q, (W) from the coolant to the unit and from the coolant to the walls of the guiding device formula of Newton-Richman (Dolgushin et al., 2015):

$$
\mathrm{Q}=\alpha \cdot \Delta \mathrm{T} \cdot \mathrm{F}
$$

Where:

$\alpha=$ Coefficient of heat transfer, $\alpha=\mathrm{f}\left(\mathrm{w}, \rho, \lambda, \mathrm{c}_{\mathrm{p}}, \mu, \beta, \mathrm{g}\right.$, $\mathrm{L}, \mathrm{F}) \mathrm{W} /\left(\mathrm{m}^{2 \circ} \mathrm{C}\right)$

$\Delta \mathrm{T}=$ Temperature difference between the coolant and the object that is being heated $\left({ }^{\circ} \mathrm{C}\right)$

$\mathrm{F}=$ Active surface area of the unit $\left(\mathrm{m}^{2}\right)$

In the case of coolant washing the surface of the plate, the heat transfer coefficient is determined by the formula (Dolgushin et al., 2015):

$$
\alpha=\frac{\mathrm{Nu} \cdot \lambda_{\mathrm{f}}}{2 \mathrm{x}}
$$

Where:

$\mathrm{Nu}=$ Nusselt number $\mathrm{Nu}=0.021 \cdot \operatorname{Re}^{0.8} \cdot \operatorname{Pr}^{0.43}$

$\lambda_{\mathrm{f}}=$ Coefficient of heat conductivity of the coolant $\mathrm{W} /\left(\mathrm{m} \cdot{ }^{\circ} \mathrm{C}\right)$

$\mathrm{x} \quad=$ The length of the surface of the plate that is being washed (m)

After transformations heat transfer coefficient $(\alpha)$ becomes:

$$
\begin{aligned}
& \alpha=0.021 \cdot\left(\frac{\mathrm{v} \cdot 2 \mathrm{x}}{\mu}\right)^{0.8} \cdot\left(\frac{\mu \cdot \mathrm{C}_{\mathrm{p}}}{\lambda_{\mathrm{f}}}\right)^{0.43} \cdot \frac{\lambda_{\mathrm{f}}}{2 \mathrm{x}}= \\
& 0.021 \cdot \frac{\mathrm{v}^{0.8} \cdot \mathrm{C}_{\mathrm{p}}^{0.43} \cdot \lambda^{0.57}}{\mu^{0.37} \cdot(2 \mathrm{x})^{0.2}}
\end{aligned}
$$

where, $\mathrm{C}_{\mathrm{p}}$ is bulk heat capacity of the coolant $\left(\mathrm{J} / \mathrm{kg} \cdot{ }^{\circ} \mathrm{C}\right)$. From temperature balance, we figure out the losses of heat by the coolant, leaving the guide device when the heat is transferred from the coolant to the unit that is being heated:

$$
\mathrm{Q}_{\text {nomer } \mathrm{b}}=\mathrm{Q}_{0 \text { ?op }}-\frac{0.021 \cdot \mathrm{v}^{0.8} \cdot \mathrm{C}_{\mathrm{p}}^{0.43} \cdot \lambda^{0.57} \cdot \mathrm{F}}{\mu^{0.37} \cdot(2 \mathrm{x})^{0.2}} \cdot\left(\mathrm{T}_{\Gamma \mathrm{BC}}-\mathrm{T}_{\text {Hap }}\right)
$$


(a)

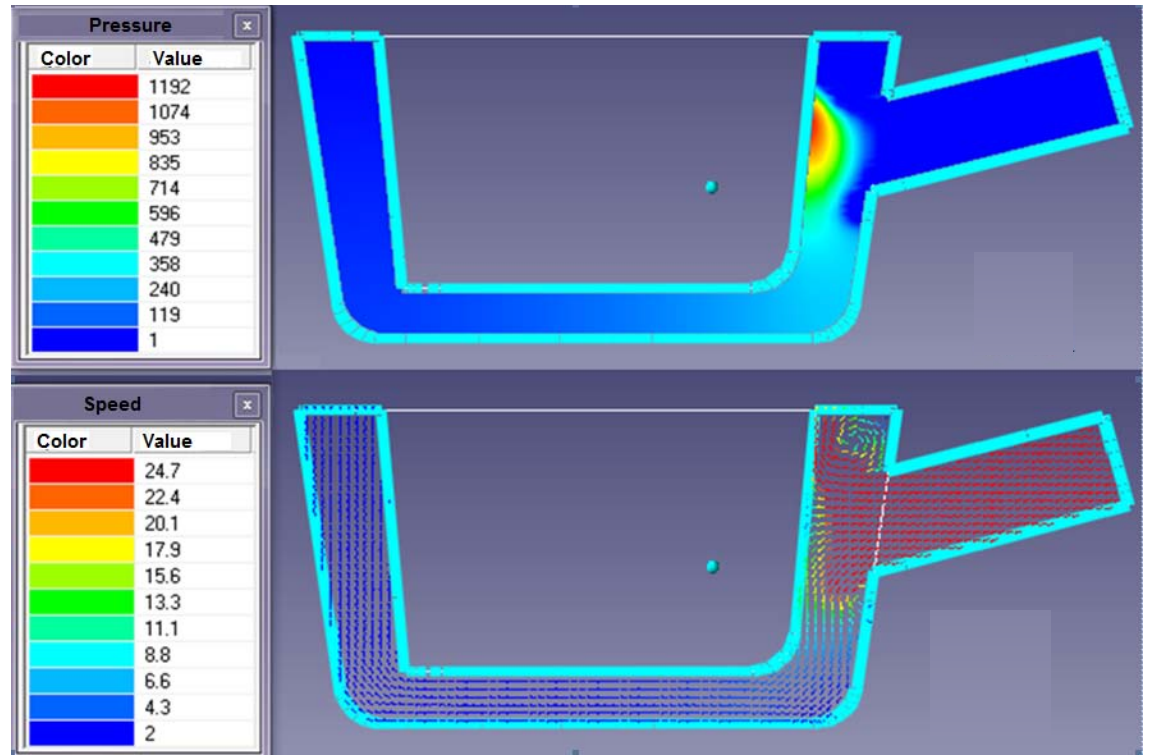

Fig. 1: Calculation of velocity fields and pressure on the example of oil pan from KAMAZ 740.30; a) Pressure field P, Пa and b) Speed field $\mathrm{V}(\mathrm{m} / \mathrm{sec})$ and the direction of vector velocity $(\mathrm{W})$

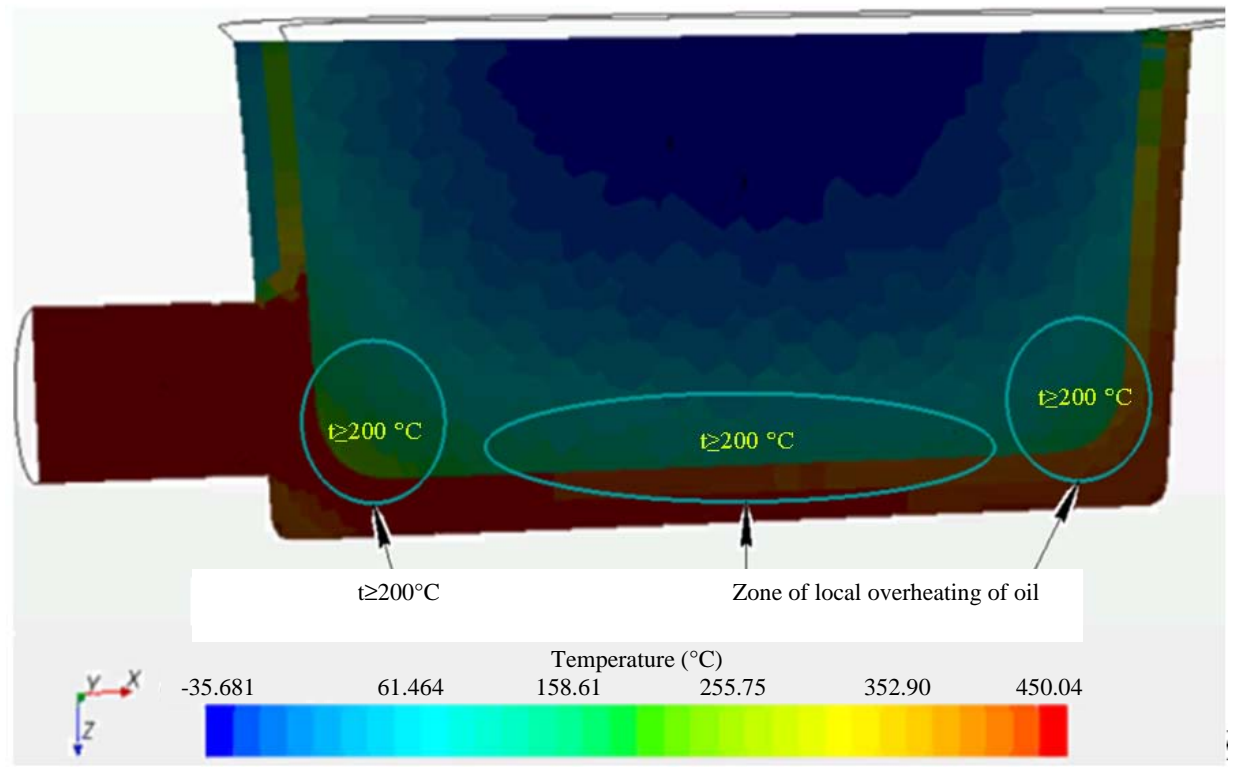

Fig. 2: Results of computer simulation of the heating of its crankcase with a coolant at a temperature of $\left(450^{\circ} \mathrm{C}\right)$

The use of this expression makes it possible to establish a quantitative relationship between the physical properties of the coolant and the intensity of heat transfer during the thermal preparation of machine preparation. The heating process was modeled on the example of KAMAZ 730.40 engine in Software CD Adapco Star CCM environment (Tursunov et al., 2014). Figure 2 shows the results of computer simulation of the heating of its crankcase with a coolant at a temperature of $450^{\circ} \mathrm{C}$. The visualization of calculation results clearly shows the presence of zones of local overheating of oil and parts of heated units.

Such overheating zones will undoubtedly lead to the failure of mechanisms, sensors and other electronic components of heated units (Jabborov et al., 2015). For guaranteed elimination of damages of non-metallic parts 


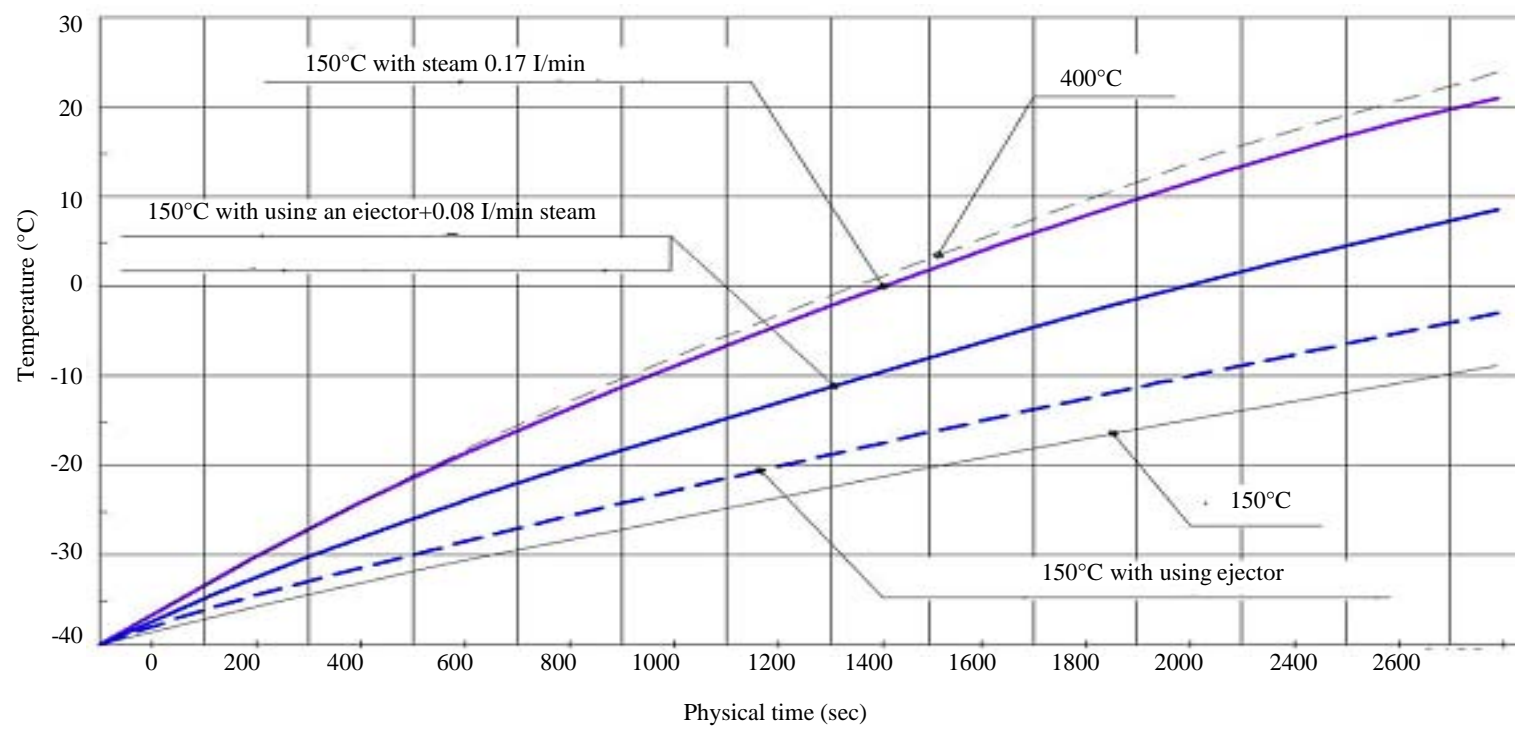

Fig. 3: Change in the average oil temperature in the crankcase of the KAMAZ 740.30 engine in physical time using a coolant with different thermal properties

of units, including electronics, they need to be heated by gas-air mixture having a temperature of no higher than $150^{\circ} \mathrm{C}$.

In the program "CD Adapco Star CCM" the calculation of the oil heating process in the oil pan of the KAMAZ 740.30 engine was carried out with 5 different types of coolant simulating a direct reduction of its temperature:

- Change in the operating mode of the gas-air mixture generator (up to $400^{\circ} \mathrm{C}$ )

- Change in the operating mode of the gas-air mixture generator (up to $150^{\circ} \mathrm{C}$ )

- Using an ejector and supplying water at a flow rate of $0.08 \mathrm{l} / \mathrm{min}$ to the hot water stream (up to $150^{\circ} \mathrm{C}$ )

- Only by supplying water at a flow rate of $0.17 \mathrm{1} / \mathrm{min}$ to the gas-air mixture flow (up to $150^{\circ} \mathrm{C}$ )

The initial heating temperature is minus $40^{\circ} \mathrm{C}$. The calculation was made over a period of $2600 \mathrm{sec}$ of heating. The criterion of efficiency was the minimum time to reach the target temperature of $+10^{\circ} \mathrm{C}$. A generalized graph of the change in the average oil temperature in the crankcase of the KAMAZ 740.30 engine in physical time using a coolant with different thermal properties is shown in Fig. 3.

The time for heating the oil to the target temperature with a mixed coolant at a temperature of $150^{\circ} \mathrm{C}$ was $2000 \mathrm{sec}$ which corresponds to a dry coolant with a temperature of $400^{\circ} \mathrm{C}$. Thus, it is confirmed a significant influence of the properties of the coolant on the intensity of heating, which makes it possible to recommend a decrease in the temperature of the gas-air mixture to reduce the risk of thermal damage without increasing the time of heat preparation.

The justification of the modes of water supply to the gas-air mixture flow for rational reduction of the coolant temperature was carried out by solving the system of equations of two-phase flows, including the Navier-Stokes equation for describing the motion of the gas-air mixture stream and the equations of the dynamics of water particles, conservation of momentum for the carrier phase and process continuity modeled in the flow vision software environment.

It was found that the most effective way to reduce the temperature of the coolant in the considered system of heat preparation is the formation of a mixed-type coolant by adding water in a volume of $0.17 \mathrm{l} / \mathrm{min}$. in the gas-air mixture stream. A further increase in the water supply does not significantly reduce the temperature of the gas-air mixture but leads to the formation of water droplets on the walls of the supply branch pipe. To determine the required water flow rate $\mathrm{g}_{\mathrm{b}}(\mathrm{kg} / \mathrm{sec})$ required to form a mixed-type coolant with a given temperature, the following expression was derived:

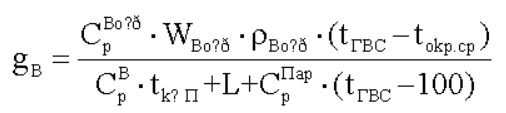

Where:

$\mathrm{C}^{\text {6030 }}{ }_{\mathrm{P}}=$ Specific mass heat capacity of air $(\mathrm{J} / \mathrm{kg} \cdot \mathrm{K})$

$\mathrm{W}_{\text {Boзð }}=$ Volumetric air flow $\left(\mathrm{m}^{3} / \mathrm{h}\right)$

$\rho_{\text {80зб }}=$ Density of air at the inlet to the heater $\left(\mathrm{kg} / \mathrm{m}^{3}\right)$

$\mathrm{t}_{\mathrm{rBC}}=$ Gas-air mixture temperature at the heater output 
$\mathrm{t}_{\text {okp.cp }}=$ The ambient temperature $\left({ }^{\circ} \mathrm{C}\right)$

$\mathrm{C}_{\mathrm{p}}^{6}=$ Specific mass heat capacity of water $(\mathrm{J} / \mathrm{kg} \cdot \mathrm{K})$

$\mathrm{L} \quad=$ The heat of vaporization $(\mathrm{J} / \mathrm{kg})$

$\mathrm{C}_{\mathrm{p}}^{\mathrm{map}}=$ Specific mass heat capacity of steam $(\mathrm{J} / \mathrm{kg} \cdot \mathrm{K})$

$\mathrm{t}_{\mathrm{k} \text { III }}=$ The boiling point $\left({ }^{\circ} \mathrm{C}\right)$

\section{RESULTS AND DISCUSSION}

The resulting equations can be used to calculate water flow rate to maintain required coolant temperature operating at full heater capacity at different surrounding temperatures (Fig. 4). The data received by calculation was tested during experimental studies and showed good convergence. Thus, the resulting equations can be used to determine the necessary operating modes of the heater and the steam generator to implement the required coolant temperature at heat preparation of farm machinery.

Further experiments were aimed to keep predetermined heating level of the machinery while coolant temperature is reduced to the safe value of $150^{\circ} \mathrm{C}$. To lower gas-air mixture temperature without decreasing coolant heat capacity two types of nozzles were used an ejector and a steam generator. As a heated machinery we used a 61 water tank.

To increase efficiency of heat preparation by a mixed coolant it is necessary to maintain the best ratio of steam and hot gases, it is indicated by full water consumption for steam generation. To prevent water drop production in the guiding device there is the best calculated length of the tube from the combustion can to the guiding device. The results are presented as a three-dimensional diagram in Fig. 5. Water flow required to make a mixed coolant is found to be dependent on heater operation mode, injected water pressure, a nozzle diameter and its injection quality.

The best values of water flow rate to generate steam for different heating modes were calculated experimentally by measuring temperature increase of the heated object in $300 \mathrm{sec}$ before heating preparation. The received data is shown in Fig. 6. The lines in the graph demonstrate the best operating parameters of the steam generator.

The experimental data gave a reasonable fit to the best parameters received by modeling the same initial
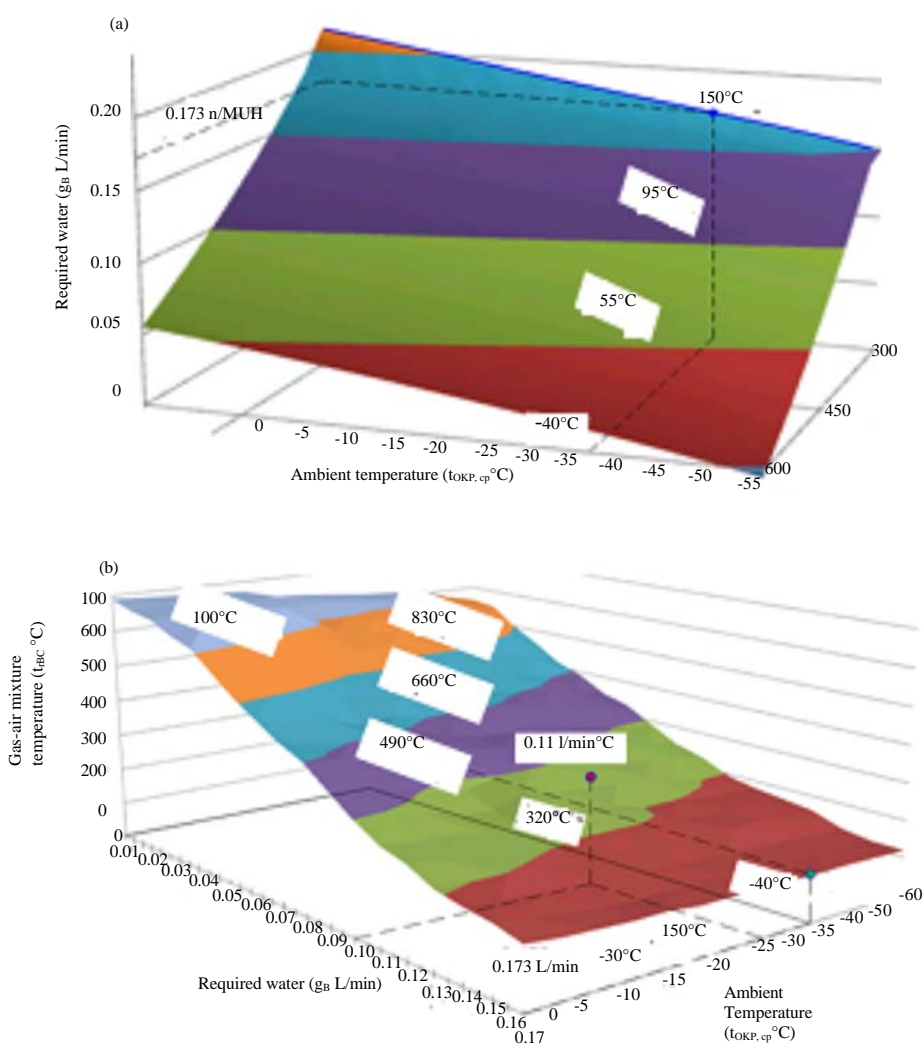

Fig. 4: Theoretical dependence of required water rate to maintain predetermined gas-air mixture temperature; a) The resulting gas-air mixture temperature depending on water flow rate and b) At different surrounding temperatures 


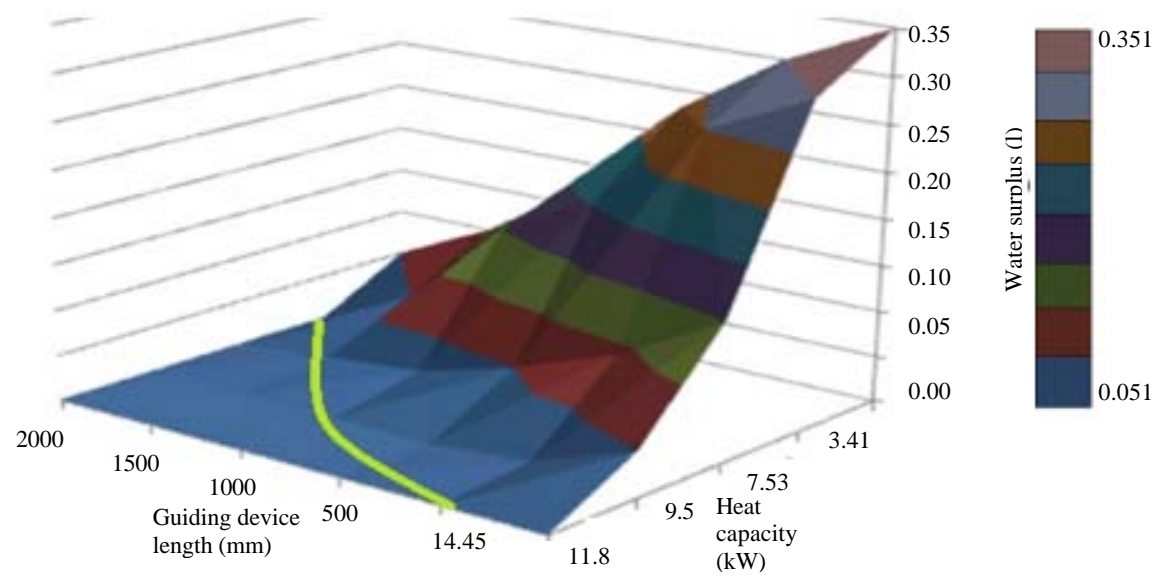

Fig. 5: Water surplus rate depending on the guiding device length and heat capacity

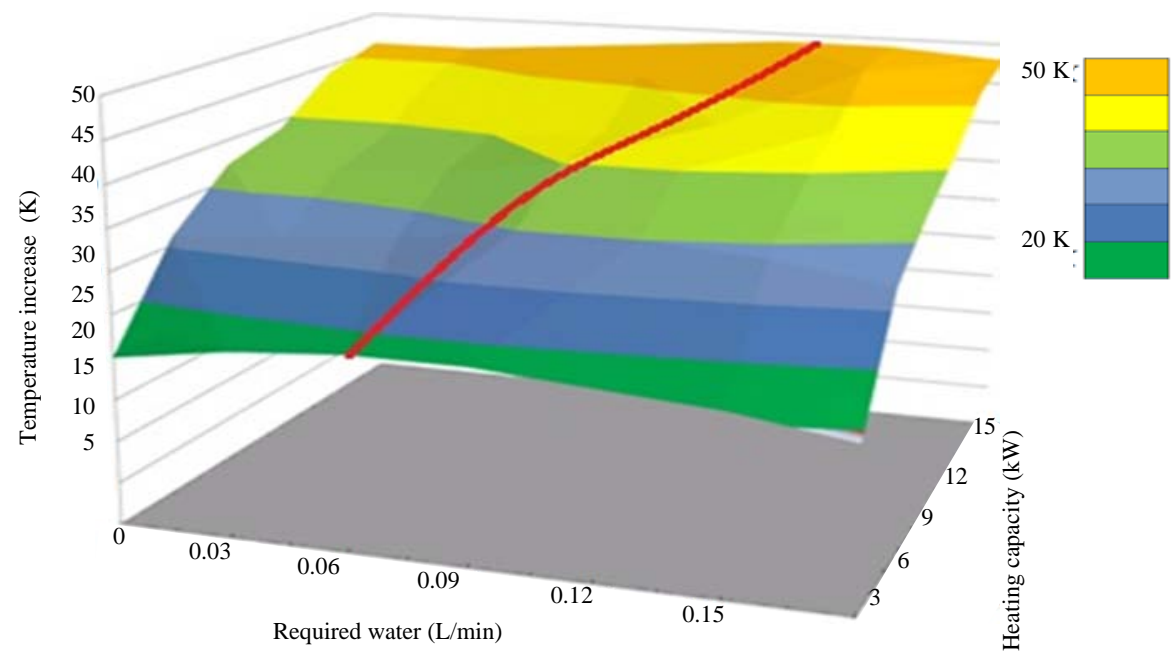

Fig. 6: Temperature increase of the heated object depending on the heater's heating capacity and water flow rate

conditions in "Adapco Star CCM" Software. Compared data, received by a theoretical and an experimental ways, is given in Fig. 7.

The conducted studies revealed an equation of water flow rate for steam generation dependence on an injector diameter, there are grounds for the minimum length of the guiding device, the best water flow rate to generate steam depending on the heater's heating capacity is determined. The conducted studies revealed higher efficiency of heating preparation when a coolant of the mixed type is used. Thus, when the coolant temperature falls from $482-317^{\circ} \mathrm{C}$ (at $34.2 \%$ ) the average heating rate increases from $2.43-2.53^{\circ} \mathrm{C} / \mathrm{min}$ (at $4.1 \%$ ). During the experiment there was also a visual comparison and measuring of frost width on engine parts and in the engine room when heating in different ways. There are no evident differences, the highest frost width on the top of the engine was $0.3, \ldots, 0.5 \mathrm{~mm}$ in different heating ways. Integrated heat preparation as well as operation of a liquid prestart heater make it possible to exclude frost formation. In addition the developed way of heat preparation enables to lower risks of thermal damage for non-metal parts and electronics of modern farm machinery. 


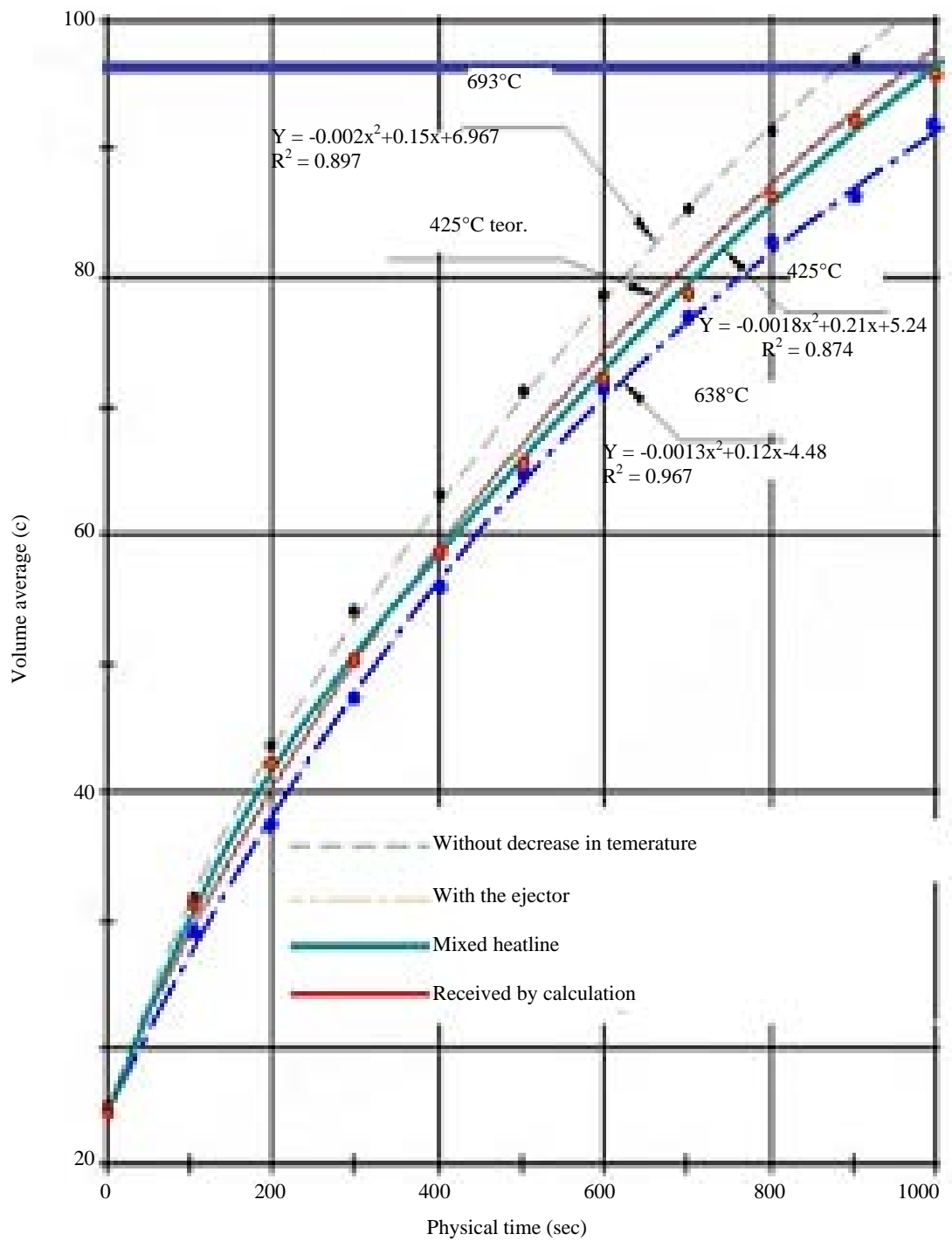

Fig. 7: Comparing three heating ways data being modeled in "Adapco Star CCM" Software object depending on the heater's heating capacity and water flow rate

\section{CONCLUSION}

The following marks have been proved. The most effective heat preparation for high-technology machinery to get a load is their volume heating with a coolant water flow at the reduced temperature of $150^{\circ} \mathrm{C}$ and parameters, determined by the guiding device and the steam generator.

There are mathematic equations to describe interaction of the coolant water flow with the heated object, thermophysical properties of the coolant and design specifics of fitters on heating rate are revealed. It is shown that to maintain minimal heat preparation of the coolant at low temperature the best water flow rate from the guiding device to the machinery walls $5 \mathrm{~m} / \mathrm{sec}$ while water consumption to get a coolant of the mixed type is to be $0.17 \mathrm{~L} / \mathrm{min}$ at heater's heat capacity of $15 \mathrm{~kW}$.

There are quantity interrelations between physical properties of the coolant and heat transmission rate during the process of heat preparation of farm machinery. On the example of the KAMAZ 740.30 engine the time to heat lubricant to the target temperature by the mixed coolant at $150^{\circ} \mathrm{C}$ corresponds to the dry coolant operating at $400^{\circ} \mathrm{C}$. Thus, there is evidence of possible reduced gas-air mixture temperature to lower the risks of thermal damage without longer heat preparation. 


\section{REFERENCES}

Bals, R., E. Pfeifer and P. Lewe, 2008. [Direct Exhaust Heat Utilization on the Gasoline Engine]. In: Thermal Management of Motor Vehicle VI, Steinberg, P. (Ed.). Expert Verlag GmbH, Ehningen, Germany, ISBN:978-3-8169-2820-1, pp: 50-68 (In German).

Bogdanic, M., 2007. [Simulation of car exhaust systems]. Ph.D Thesis, Technical University of Berlin, Berlin, Germany. (In German)

Dolgushin, A.A., A.F. Kurnosov, M.V. Vakulenko and D.A. Domnyshev, 2015. Studies of heating modes for car transmision and suspension systems in winter conditions. Sci. Technol. Achiev. Agric., 29: 82-84.

Gabitov, I.I. and A.V. Negovora, 2015. Advanced technologies in maintenance and repair of diesel fuel equipment. Bull. Bashkir State Agrar. Univ., 3: 40-44.

Gabitov, I.I., A.V. Negovora, D.A. Gusev and R.A. Bairamov, 2007. A device for oil steam heating in internal combustion engines. Utility model No. 61359 , Russian Federation: MPK 7 F02N 17/02/, Russia.

Georg, H., 2010. [Direct use of exhaust enthalpy to increase the efficiency of motor vehicles]. MSc Thesis, Technical University of Munich,Munich, Germany. (In German)
Henein, N.A., 2007. White smoke emissions in diesel engines. Master Thesis, Wayne State University, Detroit, Michigan.

Jabborov, N.I., V.A. Eviev, B.I. Belyaeva and N.G. Ochirov, 2015. Estimation of operation efficiency of machine-tractor units equipped with constant power engines. Res. J. Pharm. Biol. Chem. Sci., 6: 1793-1802.

Liebl, J., S. Neugebauer, A. Eder, M. Linde and B. Mazar, 2009. [The thermoelectric generator from BMW makes waste heat usable (In German)]. Motortechnische Z., 70: 272-281.

Negovora, A.V. and D.A. Gusev, 2013. A mixed type coolant to increase heat preparation efficiency of farm machinery. Bull. Intl. Acad. Agrar. Equip., 4: 196-198.

Negovora, A.V. and D.A. Gusev, 2017. Lower risks of thermal damage of machinery at heat preparation of cars and tractors. MSc Thesis, St. Petersburg State Agrarian University, Petersburg, Russia.

Negovora, A.V. and R.A. Bairamov, 2008. Improving a prestart preparation of diesel engines in cars and tractors at low temperatures. Tractors Farm Mach., 5: 49-50.

Tursunov, A.A., T.I. Salova and B.Z. Mazhitov, 2014. Analysis of operation conditions impact on environmental performance of internal combustion engines. Bull. Tajik Eng. Univ., 1:129-134. 